\title{
EVALUATION OF METHODOLOGY FOR DETERMINATION OF MECHANICAL EFFICIENCY OF SPARK IGNITION ENGINE
}

\author{
Daniels Levickis ${ }^{1}$, Maris Gailis ${ }^{1,2}$, Janis Rudzitis ${ }^{1}$, Juris Kreicbergs ${ }^{1}$ \\ ${ }^{1}$ Riga Technical University, Latvia; ${ }^{2}$ Latvia University of Life Sciences and Technologies, Latvia \\ levickis.daniels@gmail.com, maris.gailis@ rtu.lv, janis.rudzitis_1@rtu.lv, juris.kreicbergs@ rtu.lv
}

\begin{abstract}
Measurement of total friction of the internal combustion engine typically requires accurate, crank angle resolved measurement of the cylinder pressure and simultaneous measurement of the brake torque. Instrumentation complexity and expenses limit such measurements to scientific research domain. Simplified commercial research or educational work require less expensive and less time consuming methods. Alternative method for engine friction measurement, Morse test, requires only measurement of the brake torque and engine speed. The results of the experimental measurement of the engine friction, obtained by indicated pressure analysis and Morse test are compared and discussed. The Morse test was found to be a sufficiently accurate method for friction measurement at low load conditions.
\end{abstract}

Keywords: Morse test, internal combustion, ICE, IMEP, FMEP, friction.

\section{Introduction}

Use of internal combustion engines largely contributes to depletion of natural resources and production of greenhouse-effect gas (GHG) emissions. Transport means are mainly powered by internal combustion engines and are accounted for $33 \%$ of energy consumption in the EU [1]. During operation of the engine, the fuel's chemical energy is being converted to mechanical work - rotation of the engine crankshaft. Increase of engine efficiency is one of the key aspects to reduce specific fuel consumption and GHG emissions. The mechanical efficiency of the engine represents a fraction of the work to overcome friction of the moving engine parts, to drive auxiliary devices, such as oil pump, and it also includes the work required for the cylinder gas exchange. Mechanical efficiency of a spark ignition engine is varying from $0 \%$ at idle speed to $90 \%$ at high load and low engine speed [2]. Increase of mechanical efficiency is an ongoing subject of the academic and commercial research. Main subjects are improvement of tribological contact, use of special coatings and development of lubricants and lubricant additives [3;4]. The main contributor to frictional loses is the piston ring action in the cylinder liner $[3 ; 5 ; 6]$. Measurement of friction for specific tribological pair requires building of a specialized testing device [7]. Smith et al. describe an advanced measurement system for the piston assembly friction. It is based on measuring the force on the floating liner [8]. To measure general friction of the engine, several methods are known:

- Indicated method;

- Direct motoring test;

- Willans line;

- Analysis of engine speed;

- Morse test [2;9].

The indicated method allows true measurement of friction. The method requires accurate measurement of the crankshaft position, cylinder pressure and brake torque [2;10]. These requirements are difficult and expensive to fulfil on some practical engines.

Direct motoring tests require an active test rig, on which motoring of a complete engine is possible. The test cannot be done of test rigs with the water brake or eddy current brake.

Willans line test is applicable only to un-throttled compression ignition engines.

Analysis of the engine speed variations is a promising method. Uncertainty of the results increases in multi-cylinder engines [11]. Cruz-Pergaon et al. advanced this method and applied it to a three cylinder engine. For successful application of this method coefficients that describe torque losses for steady-state conditions must be generated. The method could be useful for diagnostics of known engines [9].

Morse test is a traditional and relatively simple method for friction measurement. It requires measurement of the engine speed and torque. The measurements can be crank-angle non-resolved. Therefore, the required instrumentation level of the test engine is comparably low. It is useful for 
simplified commercial research or educational work. The limits and uncertainty of this method, comparing to the methods, which are considered more accurate, are not well documented.

Experimental results of friction measurement by indicated and Morse methods are presented and discussed.

\section{Materials and methods}

Measurements of mechanical efficiency were performed on an automotive engine, with the main parameters summarized in Table 1.

Table 1

Main parameters of test engine

\begin{tabular}{|c|c|}
\hline Parameter & Value \\
\hline Type & Toyota 4AFE; spark ignition; port fuel injection \\
\hline Layout & 4 cylinder, in-line \\
\hline Displacement volume, $\mathrm{cm}^{-3}$ & 1587 \\
\hline Air supply & Atmospheric \\
\hline Compression ratio & 9.5 \\
\hline
\end{tabular}

The original engine control system was replaced by a user-controllable system VEMS 3.6. The system allows control of the ignition coil charge time, spark angle, injector closing angle and air-fuel mixture in open or closed loop with a wide band oxygen sensor. Engine accessories, such as the alternator, were removed. Only coolant and oil pumps were driven by the engine.

The engine was placed on the frame and the crankshaft output connected to the water brake, type Schenck U1 16h, using a splined tubular shaft and two universal joints. The setup is shown in Fig. 1.

The brake force was measured using a tenzoresistive sensor $S 2 M / 1000 N$. Brake torque (T) was calculated by multiplying the length of the load cell arm with the brake force. Crankshaft position was measured using the encoder Kistler $2613 B$ with resolution 0.1 degree. Cylinder pressure was measured by a piezoelectric transducer Kistler 6118BFD16 and charge amplifier Kistler 5018A. Only the cylinder 1, located at the crankshaft pulley end, was fitted with the pressure sensor. Data were recorded using National Instruments chassis NI-9068 and various modules, corresponding to the signal type. Software for data acquisition was based on NI LabView 2015. Data were processed and the results calculated by the script, run on Matlab R2017b.

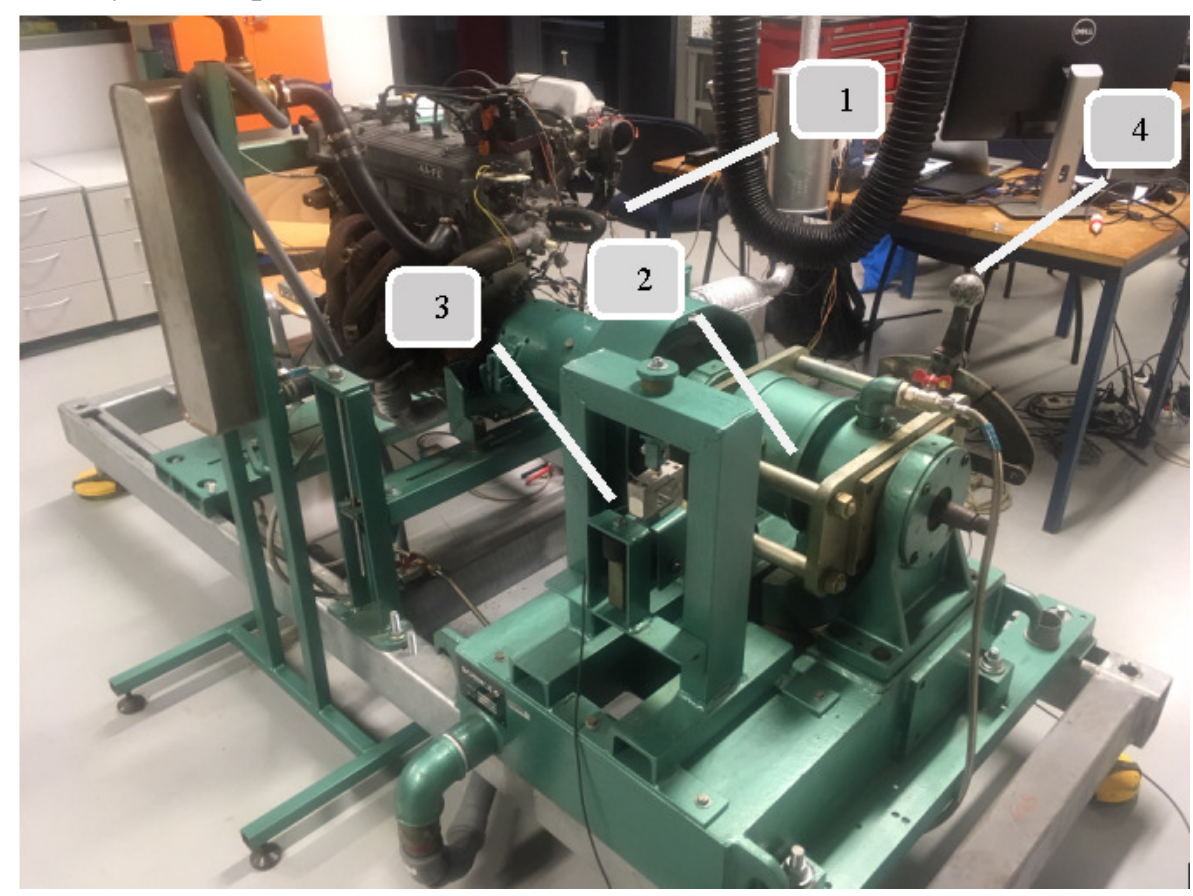

Fig. 1. Test engine setup: 1 - engine; 2 - water brake; 3 - force sensor; 4 - brake control lever 
Before testing the engine was verified mechanically, by checking the oil pressure and compression pressure in the cylinders. Engine oil grade SAE 5W40 and commercial gasoline RON95 were used. The engine was warmed up for 30 minutes to reach the nominal coolant temperature $84 \ldots 86^{\circ} \mathrm{C}$. The engine speed was $1500 \mathrm{~min}^{-1}$ during all testing conditions and modes. Engine load was 2; 3 and 4 bar brake mean effective pressure (BMEP). During testing the fuel-air mixture was held close to the stoichiometric, spark angle held constant at 14 degrees before the top dead centre (TDC). Cylinder pressure and brake force data were acquired on the crank angle (CAD) domain, with resolution of 0.1 CAD. Cylinder pressure data were converted from relative to absolute pressure by the thermodynamic method. Data of 100 successive engine cycles were acquired and averaged. Instead of torque or power, mean effective pressure was used, as it represents normalised measurement of the engine performance, and the results are comparable with engines of other type and size.

The method, based on finding the friction mean effective pressure (FMEP) and mechanical efficiency $\left(\eta_{m}\right)$ from the indicated parameters, was chosen as the base. The indicated test is described in [2], [12]. Gross indicated mean pressure $\left(I M E P_{g}\right)$ and the net indicated mean pressure $\left(\operatorname{IMEP}_{\mathrm{n}}\right)$ of the engine cylinder were calculated from the synchronised cylinder pressure and volume data:

$$
I M E P=\int_{A}^{B} \frac{p_{i} \cdot \Delta V_{i}}{V_{d c}},
$$

where $p_{i}$ - pressure in the cylinder at i-th CAD, bar;

$\Delta V$ - change in the cylinder volume at i-th $\mathrm{CAD}, \mathrm{m}^{3}$;

$V_{d c}$ - cylinder displacement volume, $\mathrm{m}^{3}$.

A - beginning of the phase, CAD;

$\mathrm{B}-$ end of the phase, CAD.

$I M E P_{g}$ includes only compression and expansion work of the first cylinder, which is shown in Fig. 2 as enclosed area, marked as $1 . I M E P_{g}$ is calculated from 180 to 540 degrees CAD. IMEP includes all the work done by gases on the piston within a complete engine cycle, from 0 to 720 degrees CAD.

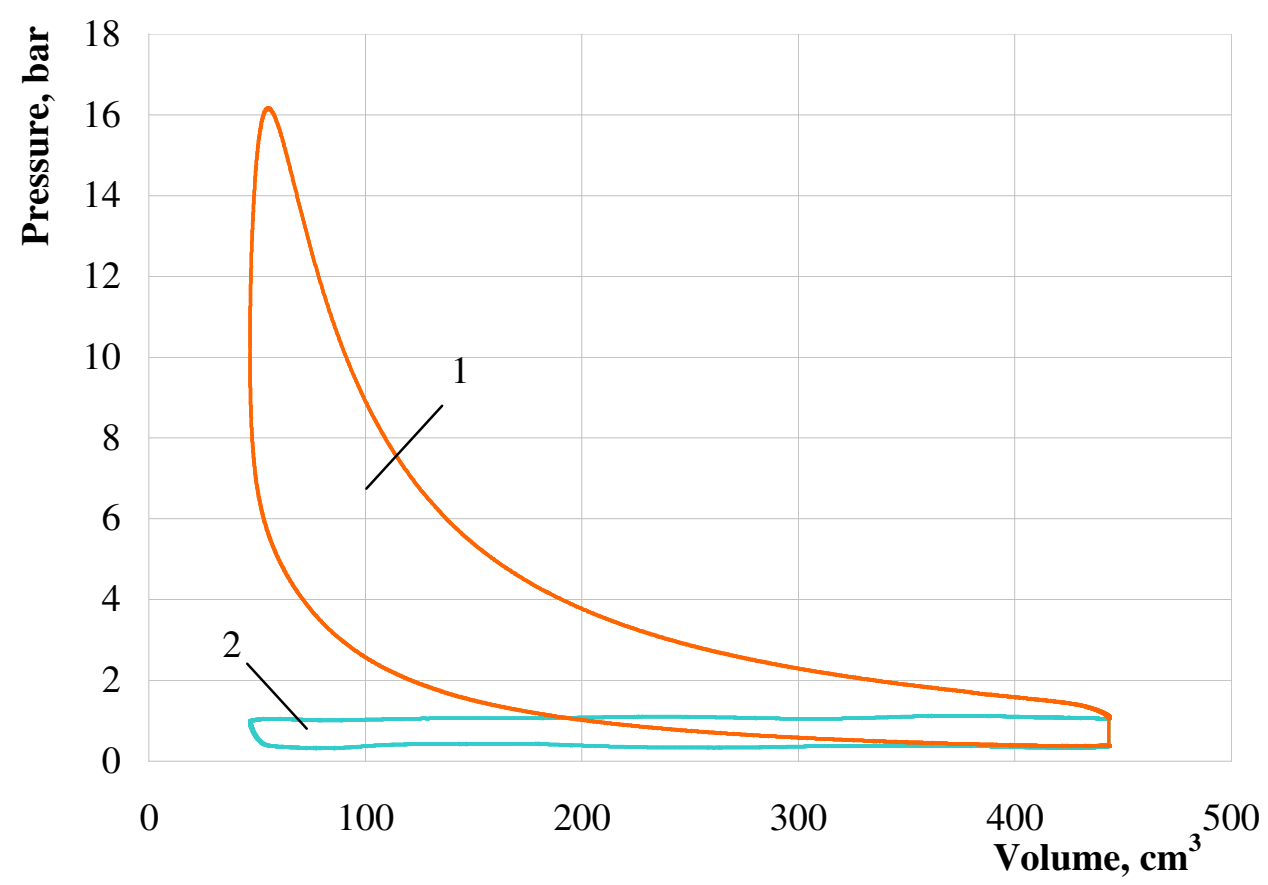

Fig. 2. Indicated work: 1 - enclosed area represents the work delivered to the piston during compression and expansion processes; 2 - enclosed area represents pumping work during inlet and exhaust processes.

$B M E P$ was calculated from the brake torque, by Eq. 2. 


$$
B M E P=\frac{T \cdot 2 \pi \cdot c \cdot 10^{-5}}{V_{d}}
$$

where $T$-brake torque, $\mathrm{Nm}$;

$\mathrm{c}$ - crankshaft rotations per engine cycle;

$V_{d}$ - engine displacement volume, $\mathrm{m}^{3}$.

$F M E P$ was calculated by the following equation:

$$
F M E P=I M E P_{g}-B M E P .
$$

FMEP includes the work required to overcome mechanical friction of the moving engine parts, accessories and pumping work required to suck in the fuel/air mixture and expel combustion products. Mechanical efficiency of the engine was calculated by Eq. 4 .

$$
\eta_{m}=\frac{B M E P}{I M E P_{g}} \cdot 100 .
$$

Morse test is an alternative method for engine friction measurement. The method is based on calculation of IMEP by switching off the engine cylinders, one at a time. Description of this method is included in [13]. Gross indicated mean pressure of the engine $\left(I M E P_{g e}\right)$ is the sum of friction and brake mean effective pressure of all engine cylinders:

$$
I M E P_{g e}=\sum_{1}^{n} I M E P_{j}=\sum_{1}^{n} B M E P_{j}+\sum_{1}^{n} F M E P_{j},
$$

where $j$-cylinder number;

$n-$ total number of engine cylinders.

In case of firing of all cylinders of the four-cylinder engine Eq. 5 can be rewritten:

$$
I M E P_{c y l 1}+I M E P_{c y l 2}+I M E P_{c y l 3}+I M E P_{c y l 4}=B M E P_{c y l 1}+B M E P_{c y l 2}+B M E P_{c y l 3}+B M E P_{c y l 4}+\sum_{1}^{4} F M E P_{j}
$$

If combustion in the first cylinder of the engine is switched off, all the cylinders still require friction and pumping work, but the cylinder one is being motored and does not produce work:

$$
I M E P_{c y l 2}+I M E P_{c y l 3}+I M E P_{c y l 4}=B M E P_{c y l 2}+B M E P_{c y l 3}+B M E P_{c y l 4}+\sum_{1}^{4} F M E P_{j} .
$$

Engine speed is then adjusted to the value $\left(1500 \mathrm{~min}^{-1}\right)$, when all the cylinders of the engine were working. Engine speed adjustment was done by reducing the water brake load. Combustion on the selected cylinder is being cut but disconnecting the fuel injector, instead of cutting ignition, as suggested in [13]. Unburned fuel is not reaching the exhaust system, reducing the risk of explosion in the exhaust system and preserving catalytic converter. During operation with the disconnect injector the oxygen sensor was also disconnected. Fuel/ air mixture then is being regulated on the open control loop, as the feedback from the oxygen sensor will lead to overly-rich fuel/air mixture for the working cylinders. By subtracting Eq. 7 from Eq. 6, IMEP of the cylinder one is found:

$$
I M E P_{c y l 1}=\sum_{1}^{4} B M E P_{j}-\sum_{2}^{4} B M E P_{j} .
$$

$I M E P$ of the other three cylinders is found similarly. IMEP of the engine then is calculated:

$$
I M E P_{g e}=I M E P_{c y l 1}+I M E P_{c y l 2}+I M E P_{c y l 3}+I M E P_{c y l 4} \text {. }
$$

Mechanical efficiency and FMEP can be calculated, using equations similar to Eq. 3 and Eq. 4. All the tests were repeated 3 times and statistically evaluated, by calculating $95 \%$ confidence intervals. In case of several variables, such as mechanical efficiency, partial errors were calculated. 


\section{Results and discussion}

The indicated test is based on direct measurement of the brake torque on the crankshaft output and gas work on the piston. For simultaneous measurement of the gas work in the multi-cylinder engine, every cylinder must be fitted with a pressure transducer and the data acquisition system should have a multi-channel charge amplifier. In this research the indicated work was measured only in the cylinder one. Averaged pressure-volume diagrams of all test modes are shown in Fig. 3. Diagrams in logarithmic scale show good overall quality of the pressure-volume data. Finding of true piston top dead centre is important for correct estimation of IMEP. Error in $0.1^{\circ} \mathrm{CAD}$ may lead to $10 \%$ error in $I M E P$ estimation [14]. In the spark-ignition engine load is controlled mainly by restricting the air flow to the engine. As the engine load, and respectively $B M E P$, increases, the engine pumping work decreases. The effect is shown in Fig. $3 \mathrm{~b}$ as decrease of the enclosed area of the part of the curve that represents the pumping work. As the pumping work is the part of $F M E P$, mechanical efficiency may increase with increase of the load.

a)

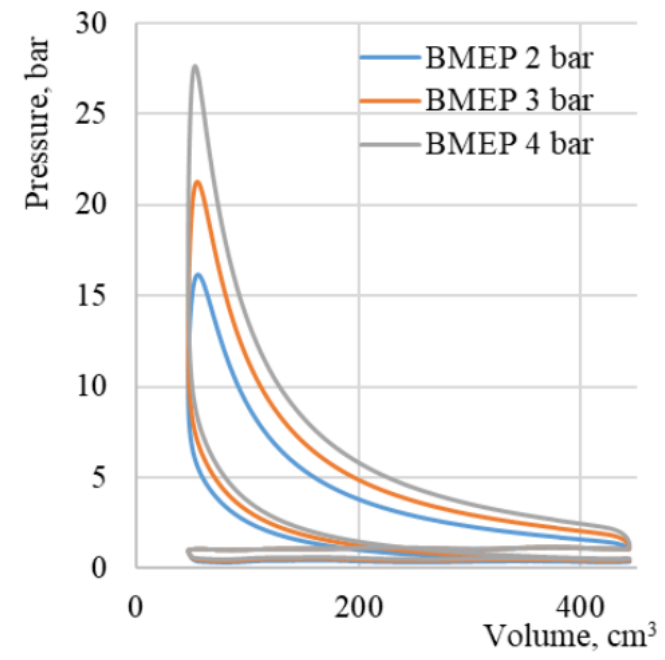

b)

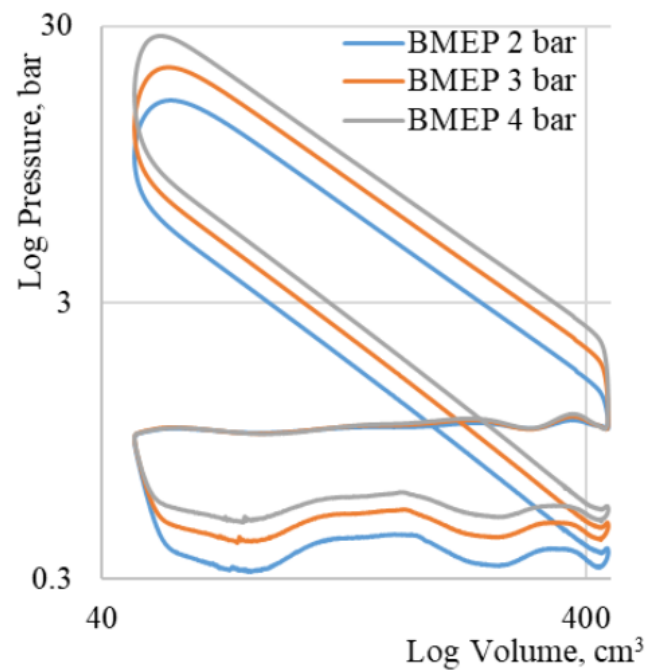

Fig. 3. Pressure-volume diagrams: $a$ - in normal scale; $b$ - in logarithmic scale

Brake torque, averaged from 100 successive engine cycles, resolved in CAD domain, is shown in Fig. 4. For the Indicated test the line, that represents all cylinders fired, is relevant. As TDC of the first cylinder is located at 360 degrees, it is apparent that the torque measurement is not synchronised with its production. The delay can be explained with specifics of the water brake and the oscillations in the mechanical drive, which connects the crankshaft to the water brake. Average value of torque per engine cycle from 100 engine cycles was used for the calculation of BMEP.

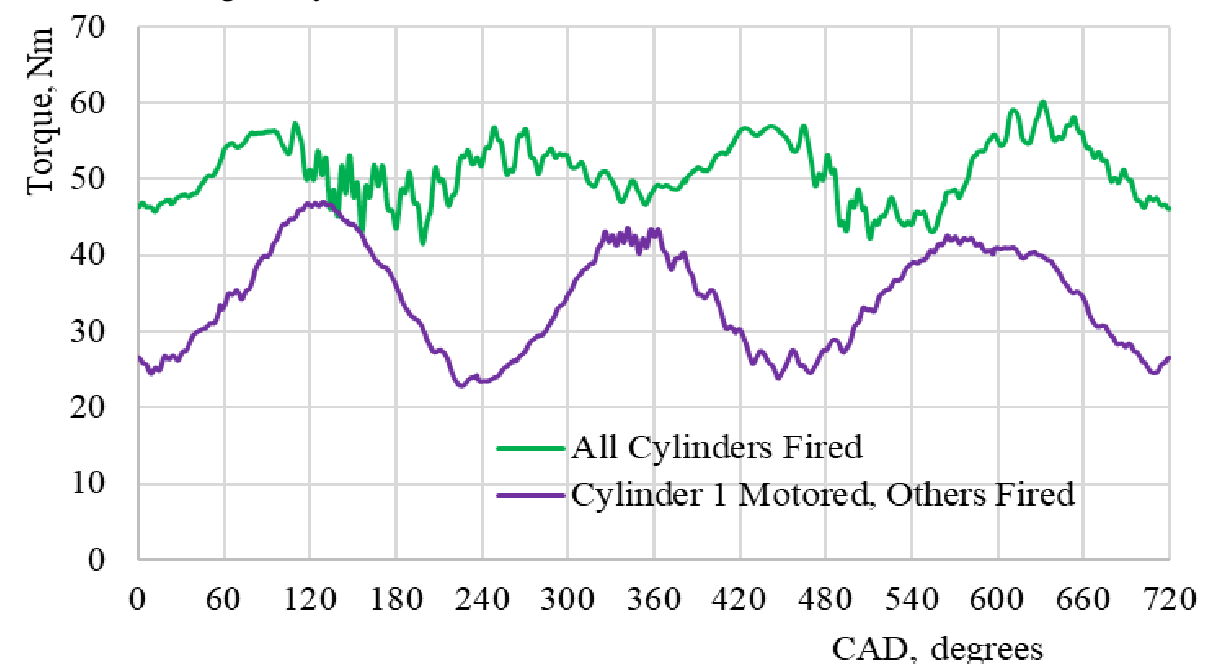

Fig. 4. Brake torque diagrams: test conditions 4 bar $B M E P$ 
Results of the Indicated test can be seen in Table 2. FMEP is reducing and mechanical efficiency increasing, as the load is increasing. Confidence interval of the mechanical efficiency is between 2.3 to $2.5 \%$

Table 2

Results of indicated test

\begin{tabular}{|c|c|c|c|c|}
\hline BMEP, bar & IMEP $_{\mathbf{g}}$, bar & IMEP $_{\mathbf{n}}$, bar & FMEP, bar & $\boldsymbol{\eta}_{\mathbf{m}}, \boldsymbol{\%}$ \\
\hline 2.04 & 3.24 & 2.54 & 1.20 & $63.1 \pm 2.4$ \\
\hline 3.03 & 4.19 & 3.57 & 1.16 & $72.4 \pm 2.5$ \\
\hline 3.99 & 5.17 & 4.62 & 1.18 & $77.2 \pm 2.3$ \\
\hline
\end{tabular}

Morse test is based on sequental motoring of the engine cylinders. It is assumed that the motored cylinder will require similar friction and pumping work as the fired one, and the difference in $B M E P$ of the engine, fired on all cylinders and the same engine, with one cylinder motored, will be equal with $\mathrm{IMEP}_{\mathrm{g}}$ of the motored cylinder. Engine speed, throttle position and fuel/air mixture strenght of the fully fired and partially motored engine must be the same [13]. Pressure-volume diagrams in logharitmic scale of fired and motored operation of the engine cylinder are shown in Fig. 5.

The pressure trace is not following the same line during compression and expansion. Negative work is done during the compression and expansion phase, which can be attributed to heat transfer from gases to the combustion chamber surface and pressure losses via piston rings and valves. Analysis of motoring data reveals that negative $I M E P_{g}$ of the motored cylinder is aproximently $3 \%$ of fired $I M E P_{g}$. As shown in Fig. 5b, the motored inlet pressure curve closely follows the inlet pressure curve during firing. Pressure curve of the exhaust process differs for motored and fired operation. During fired operation combustion products are expelled from the cylinder. In the case of motoring, exhaust gases from the exhaust manifold are entering the motored cylinder, when the exhaust valve opens. The pumping work of the motored cylinder appears reduced by $8.3 \%$, comparing to the fired operation of the same cylinder at 4 bar BMEP. The effect increases by the increase of the load.

a)

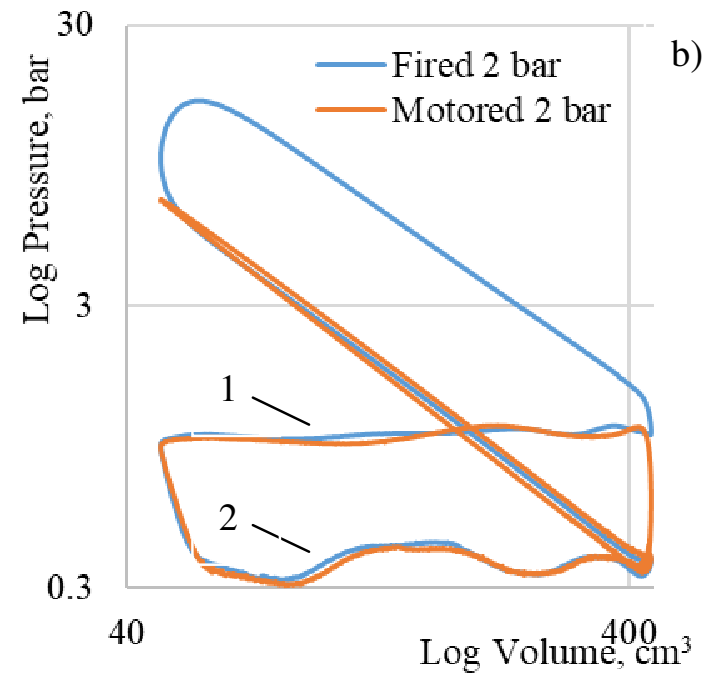

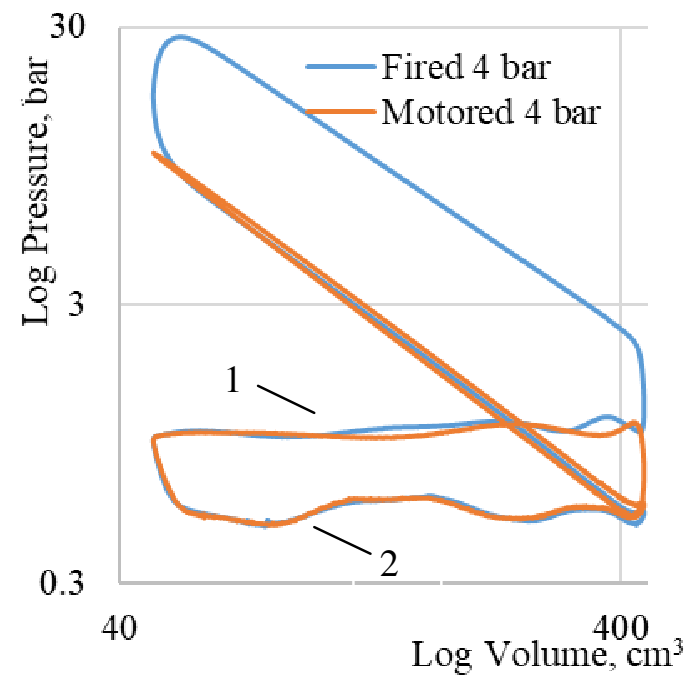

Fig. 5. Pressure-volume diagrams of fired and motored operation: $\mathrm{a}-B M E P 2 \mathrm{bar} ; \mathrm{b}-B M E P 4$ bar; 1 - exhaust pressure curve; 2 - inlet pressure curve

Results of the Morse test are presented in Table 3.

Results of Morse test

\begin{tabular}{|c|c|c|c|}
\hline $\boldsymbol{B M E P}$, bar & $\boldsymbol{I M E P}_{\boldsymbol{g}}$, bar & $\boldsymbol{F M E P}$, bar & $\boldsymbol{\eta}_{\boldsymbol{m}}, \boldsymbol{\%}$ \\
\hline 1.98 & 3.41 & 1.43 & $58.2 \pm 0.9$ \\
\hline 3.03 & 4.30 & 1.28 & $70.3 \pm 4.9$ \\
\hline 4.03 & 5.44 & 1.41 & $74.1 \pm 9.2$ \\
\hline
\end{tabular}


Comparison of the calculated mechanical efficiency, obtained by indicated and Morse tests, are presented in Fig. 6. The error bars represent $95 \%$ confidence intervals. The Morse test shows apparently reduced mechanical efficiency, comparing to the indicated test. Difference in the results is statistically insignificant. Results, obtained by Morse test, have larger uncertainty, which increases by the load.

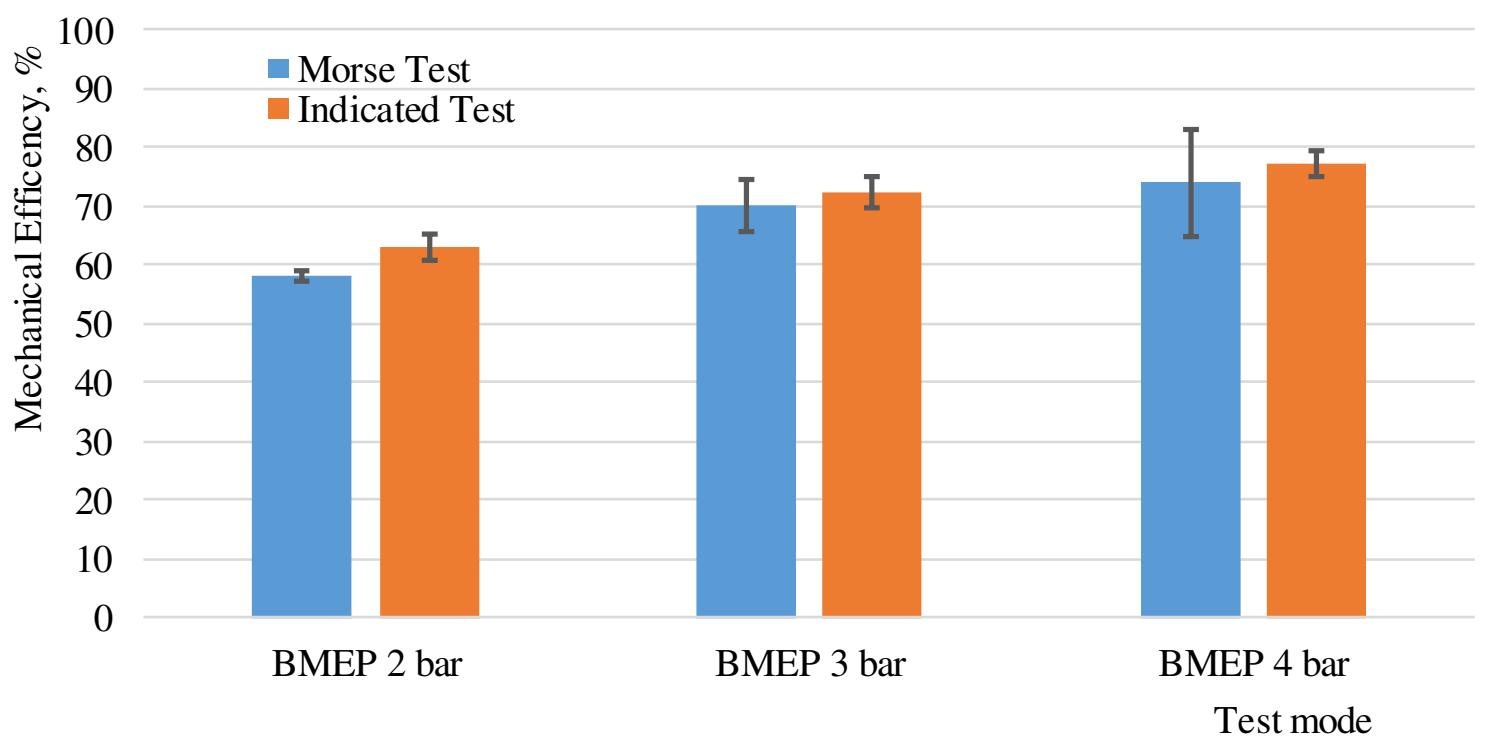

Fig. 6. Comparison of the calculated mechanical efficiency

Morse test can be applied for evaluation of engine mechanical efficiency, but appears to be limited to low load conditions due to increase of uncertainty with load.

\section{Conclusions}

1. Mechanical efficiency, obtained by the Morse test, appears to be of a smaller value, comparing to the results of the indicated test. The difference is statistically insignificant.

2. Uncertainty of the results of mechanical efficiency, obtained by the indicated test, does not exceed $2.5 \%$ in the tested conditions.

3. Uncertainty of the results of the Morse test increases by load.

4. Morse test can be applied for friction measurement for commercial or educational purposes at low load conditions, where BMEP does not exceed 2 bar.

\section{References}

[1] Report from the commission to the Europenan Parliamant and Council 2017. [online] [10.02.2019] Available at: https://eurlex.europa.eu/legalcontent/EN/TXT/?qid = 1511978095545 \&uri $=$ COM:2017:687:FIN.

[2] Heywood J.B. Internal Combustion Engine Fundamentals. New York: McGrawHill, 2018. $1028 \mathrm{p}$.

[3] Wong V. W., Tung S. C. Overview of automotive engine friction and reduction trends - Effects of surface, material, and lubricant-additive technologies. Friction, vol. 4, no. 1, 2016, pp. 1-28.

[4] Richardson D. E. Review of Power Cylinder Friction for Diesel Engines. Journal of Engineering for Gas Turbines and Power, vol. 122, no. 4, 2000, pp. 506-519.

[5] Tormos B., Martín J., Carreño R., Ramírez L. A general model to evaluate mechanical losses and auxiliary energy consumption in reciprocating internal combustion engines. Tribology. International, vol. 123, no. 1, 2018, pp. 161-179.

[6] Söderfjäll M., Herbst H. M., Larsson R., Almqvist A. Influence on friction from piston ring design, cylinder liner roughness and lubricant properties. Tribology. International, vol. 116, no. 7, 2017, pp. 272-284.

[7] Chaudhari T., Sutaria B., Investigation of friction characteristics in segmented piston ring liner assembly of IC engine. Perspectives in Science, vol. 8, 2016, pp. 599-602. 
[8] Smith E. H., I. Sherrington I., D. G. Clarke D. G. The measurement of piston assembly friction in a motored engine. Internal Combustion Engine Research in UK Universities, Colleges and Polytechnics, 1991, pp. 185-190.

[9] Cruz-Peragón F., Palomar J. M., Díaz F. A., Jiménez-Espadafor F. J. Fast on-line identification of instantaneous mechanical losses in internal combustion engines. Mechanical Systems and Signal Processing, vol. 24, no. 1, 2010, pp. 267-280.

[10]Rogers D. R. Engine Combustion: Pressure Measurement and Analysis. Warrendale: SAE International, 2010, $332 \mathrm{p}$.

[11] Rezeka S. F., Henein N. A. A New Approach to Evaluate Instantaneous Friction and Its Components in Internal Combustion Engines. SAE International Congress and Exposition, 1984, p. 16.

[12] Stone R. Introduction to Internal Combusiton Engines, Third editon. New York: Palgrave Macmillian, 1999, $641 \mathrm{p}$.

[13] Ganesanen V. Intern al Combustion Engines. New Delhi: Tata McGraw-Hill, 2013. 777 p.

[14]Lancaster D. R., Krieger, R. B., Lienesch J. H. Measurement and Analysis of Engine Pressure Data, SAE International Congress and Exposition, 1975, p. 18. 